\title{
Doses e épocas de aplicação de potássio na cultura da soja em sucessão a plantas de cobertura
}

\author{
Doses and application seasons of potassium on soybean crop in \\ succession the cover crops
}

\author{
Amilton Ferreira da Silva ${ }^{1 *}$; Edson Lazarini ${ }^{2}$
}

\section{Resumo}

O potássio $(\mathrm{K})$ é o segundo nutriente requerido em maior quantidade pela cultura da soja. Com a utilização de altas doses e aumento das áreas de plantio direto nos últimos anos, ocorreram algumas mudanças nas formas de aplicação desse nutriente, bem como, a introdução de plantas de cobertura no sistema para formação de palhada. Nesse sentido, objetivou-se com esse trabalho, o estudo de doses e épocas de aplicação de potássio para a cultura da soja cultivada em sucessão a plantas de cobertura em sistema de plantio direto num Latossolo Vermelho distrófico argiloso (LVd) na região de cerrado. $\mathrm{O}$ delineamento experimental utilizado foi em blocos ao acaso, com os tratamentos dispostos em esquema

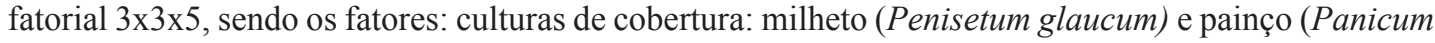
miliaceum) e um controle (pousio); doses de $\mathrm{K}_{2} \mathrm{O}\left(0 ; 50\right.$ e $\left.100 \mathrm{~kg} \mathrm{ha}^{-1}\right)$ e modos de aplicação do $\mathrm{K}(100 \%$ nas das culturas de cobertura; $100 \%$ na semeadura da soja; $100 \%$ em cobertura na soja; $50 \%$ antecipada nas culturas de cobertura $+50 \%$ na semeadura da soja; $50 \%$ na semeadura da soja $+50 \%$ em cobertura na soja.) com quatro repetições. Para análise apenas das culturas de cobertura foi utilizado o fatorial de $2 \times 3 \times 3$. O milheto como planta de cobertura antecessora a cultura da soja produz maior conteúdo de matéria seca que o painço em curto período de tempo. Em solo argiloso com alto teor de potássio não houve resposta a doses de potássio aplicadas, podendo a adubação potássica de manutenção ser aplicada totalmente antecipada na cultura de cobertura, na semeadura ou em cobertura na cultura de soja.

Palavras-chave: Plantio direto, reciclagem de nutrientes, antecipação da adubação

\begin{abstract}
Potassium $(\mathrm{K})$ is the second nutrient that is required in larger amounts by soybean crop. With the use of high doses of that nutrient and increase of no-tillage areas in last years, some changes occurred in ways of this nutrient application, as well as the introduction of cover crops in the system for straw formation. Due those facts, the aim with this work was to study doses and times of potassium application for soybean sowed as succession for cover crops in no-tillage system, in a clayey Distrofic Red Latosol, in cerrado region. The experimental design was a randomized block with treatments arranged in $3 \times 3 \times 5$ factorial scheme, with the following factors, cover crops: Pearl millet (Pennisetum glaucum) and Proso millet (Panicum miliaceum) and a control (fallow area), rates of $\mathrm{K}_{2} \mathrm{O}\left(0,50 \mathrm{e} 100 \mathrm{~kg} \mathrm{ha}^{-1}\right)$ and $\mathrm{K}_{2} \mathrm{O}$ application forms $(100 \%$ in the cover crops; $100 \%$ at sowing of soybean; $100 \%$ in topdressing in soybean; $50 \%$ at sowing cover crops $+50 \%$ at soybean sowing; $50 \%$ at soybean sowing $+50 \%$ in topdressing in the soybean) with four replicates. The Pennisetum glaucum as soybean predecessor crop yields higher dry matter content than the Panicum miliaceum in a short period of time. In clay soil with high content of potassium there was no response to the applied potassium levels. Full doses of potassium maintenance fertilization can be applied in the predecessor cover crop, at sowing or topdressing in soybean crop.

Key words: No-tillage, recycling of nutrients, anticipation of fertilization
\end{abstract}

1 Discente de Doutorado em Fitotecnia, Universidade Federal de Viçosa, UFV, Viçosa, MG. E-mail: amilton@agronomo.eng.br

2 Prof. Dr. do Dept ${ }^{\mathrm{o}}$ de Biologia Aplicada a Agropecuária, Universidade Estadual Paulista, Faculdade de Engenharia de Ilha Solteira, USP, Ilha Solteira, SP. E-mail: lazarini@agr.feis.unesp.br

* Autor para correspondência 


\section{Introdução}

A cultura da soja alcança atualmente elevados índices de produtividade, dentre os fatores responsáveis por esse aumento nas ultimas décadas está o melhoramento genético e a adubação equilibrada, capaz de proporcionar o potencial produtivo da planta, juntamente com outras práticas de manejo. Dos nutrientes requeridos em maior quantidade pela soja, o potássio é o segundo, após o nitrogênio, no entanto, o $\mathrm{N}$ atualmente é suprido pela fixação biológica, já o K deve ser aplicado no solo via fertilizantes, pois a maioria das áreas exploradas com soja no território brasileiro encontra-se em regiões tropicais, onde predominam formações de solos de elevado grau de intemperismo, com baixos níveis desse nutriente.

Em áreas onde vem sendo cultivada soja há vários anos com aplicações corretas de potássio, geralmente o teor desse nutriente tende a se equilibrar no solo, chegando a níveis de bom a alto, havendo potássio no solo suficiente para a planta por determinado período. Neste caso, os cuidados recaem sobre as quantidades exportadas pela colheita da soja que, segundo Zancanaro et al. (2009), são próximas a 20 $\mathrm{kg} \mathrm{ha}^{-1}$ de $\mathrm{K}_{2} \mathrm{O}$ para cada $1.000 \mathrm{~kg} \mathrm{ha}^{-1}$ de grãos. Por outro lado, além da exportação, devem ser consideradas as perdas por lixiviação e por erosão. Assim, a adubação de manutenção para repor essas quantidades de $\mathrm{K}$ exportadas e perdidas deve ser realizada.

O K apresenta alta mobilidade na planta, tanto no xilema, quanto no floema e não faz parte de nenhum composto orgânico na planta. Assim, após a colheita ou senescência das plantas, o K presente na fitomassa é liberado rapidamente ao solo em forma prontamente disponível para as culturas (RAIJ et al., 1997), o que caracteriza a palhada como um reservatório expressivo de $\mathrm{K}$ em curto prazo no sistema de plantio direto (ROSOLEM; CALONEGO; FOLONI, 2003). Dessa forma, plantas de cobertura cultivadas como antecessoras a cultura da soja podem ser boas opções na reciclagem desse nutriente, resultando em maior disponibilidade nas camadas superficiais do solo.

Com a consolidação do sistema de semeadura direta na região Centro-Oeste, houve mudanças nas formas de adubação da cultura da soja, objetivando a disponibilização do nutriente nos períodos de maior necessidade da cultura ou também pela otimização da semeadura em extensas áreas, a fim de elevar a produtividade associada a práticas de manejo mais eficientes. Uma das alternativas que vem sendo testada é a antecipação da adubação da soja, que passa a ser realizada na cultura antecessora utilizada normalmente como adubo verde (MATOS; SALVI; MILAN, 2006), prática essa que, segundo FRANCISCO (2002), não interfere na produtividade, além de otimizar o tempo de operação da semeadora. Porém, diferentemente do fósforo, o potássio perde-se facilmente por lixiviação. Com isso, a aplicação total desse nutriente de forma antecipada, dependendo do tipo de solo, pode não ter o aproveitamento esperado.

A adubação potássica pode ser realizada tanto no sulco de semeadura quanto a lanço (BORKERT et al., 2005b), sendo a aplicação a lanço antes da semeadura recomendada preferencialmente em solos de textura argilosa, com teores médios e bons de $\mathrm{K}$. Em relação à aplicação de $\mathrm{K}$ (na forma de $\mathrm{KCl})$ no sulco de semeadura, devido ao alto índice salino, alguns cuidados são recomendados na utilização deste fertilizante. Dentre eles, não aplicar doses superiores a $50 \mathrm{~kg} \mathrm{ha}^{-1}$ de $\mathrm{K}_{2} \mathrm{O}$ no sulco de semeadura, visando reduzir os riscos do efeito salino sobre a germinação das sementes, principalmente em condições de estresse hídrico (OLIVEIRA et al., 2008).

Dentre as alternativas de cultura de cobertura no cerrado, o milheto (Penisetum glaucum) vem sendo a mais utilizada principalmente pelo enorme potencial de cobertura do solo oferecido para a prática do plantio direto. Segundo Bonamigo (1993), a cultura do milheto como planta de cobertura em condições ideais pode produzir até $70 \mathrm{t} \mathrm{ha}^{-1}$ de fitomassa verde 
e 6,8 $\mathrm{t} \mathrm{ha}^{-1}$ de fitomassa seca. Mais recentemente, o painço (Panicum miliaceum) começou também a ser utilizado como cultura de cobertura, pois era destinado anteriormente somente para utilização na alimentação animal. Como vantagem, essa cultura possui ciclo curto (60 a 70 dias), podendo ser uma espécie interessante para o período de invernoprimavera, antecedendo a cultura da soja.

De acordo com essas observações, objetivou-se com esse trabalho, o estudo de doses e épocas de aplicação de potássio para a cultura da soja cultivada em sucessão a plantas de cobertura em sistema de plantio direto num Latossolo Vermelho distrófico argiloso (LVd) na região de cerrado.

\section{Material e Métodos}

$\mathrm{O}$ experimento foi realizado durante o ano agrícola 2009/2010, no município de Selvíria (MS), na área experimental da Fazenda de Ensino, Pesquisa e Extensão/UNESP (20 $\left.22^{\circ} \mathrm{S} ; 5^{\circ}{ }^{\circ} 22^{\prime} \mathrm{W} ; 335 \mathrm{~m}\right)$,
Campus de Ilha Solteira. O solo predominante da área é o Latossolo Vermelho distrófico (LVd) típico muito argiloso (DEMATTÊ, 1980). Nesta área, realizou-se amostragem de solo na camada de 0-0,2 m, anterior a instalação do experimento e os resultados da análise granulométrica e química do solo foram: argila $=660 \mathrm{~g} \mathrm{~kg}^{-1}$; silte $=120 \mathrm{~g} \mathrm{~kg}^{-1}$; areia $=220 \mathrm{~g} \mathrm{~kg}^{-1}$; M.O. $=17 \mathrm{~g} \mathrm{dm}^{-3} ;$ CTC $=80$ $\mathrm{mmol}_{\mathrm{c}} \mathrm{dm}^{-3} ; \mathrm{V} \%=43 ; \mathrm{pH}\left(\mathrm{CaCl}_{2}\right)=4,7 ; \mathrm{P}$ resina $=$ $35 \mathrm{mg} \mathrm{dm}^{-3} ; \mathrm{K}^{+}=4,8 \mathrm{mmol}_{\mathrm{c}} \mathrm{dm}^{-3}$ (nível muito bom), $\mathrm{Ca}^{+2}=19 \mathrm{mmol}_{\mathrm{c}} \mathrm{dm}^{-3}, \mathrm{Mg}^{+2}=11 \mathrm{mmol}_{\mathrm{c}} \mathrm{dm}^{-3} \mathrm{e}(\mathrm{H}+$ $\left.\mathrm{Al}^{+3}\right)=45 \mathrm{mmol}_{\mathrm{c}} \mathrm{dm}^{-3}$.

A área anteriormente vinha sendo cultivada com a cultura do milho, com aplicações anuais por volta de $40 \mathrm{~kg}$ de $\mathrm{K}_{2} \mathrm{O} \mathrm{ha}^{-1}$. O índice pluviométrico registrado na área durante a condução do experimento encontrase na figura 1. Houve disponibilidade hídrica suficiente para o desenvolvimento das culturas durante todo o período, com maior pluviosidade principalmente nos meses de crescimento das culturas de cobertura.

Figura 1. Precipitação pluvial média mensal registrada na área durante a condução do experimento. Selvíria - MS, 2009/2010.

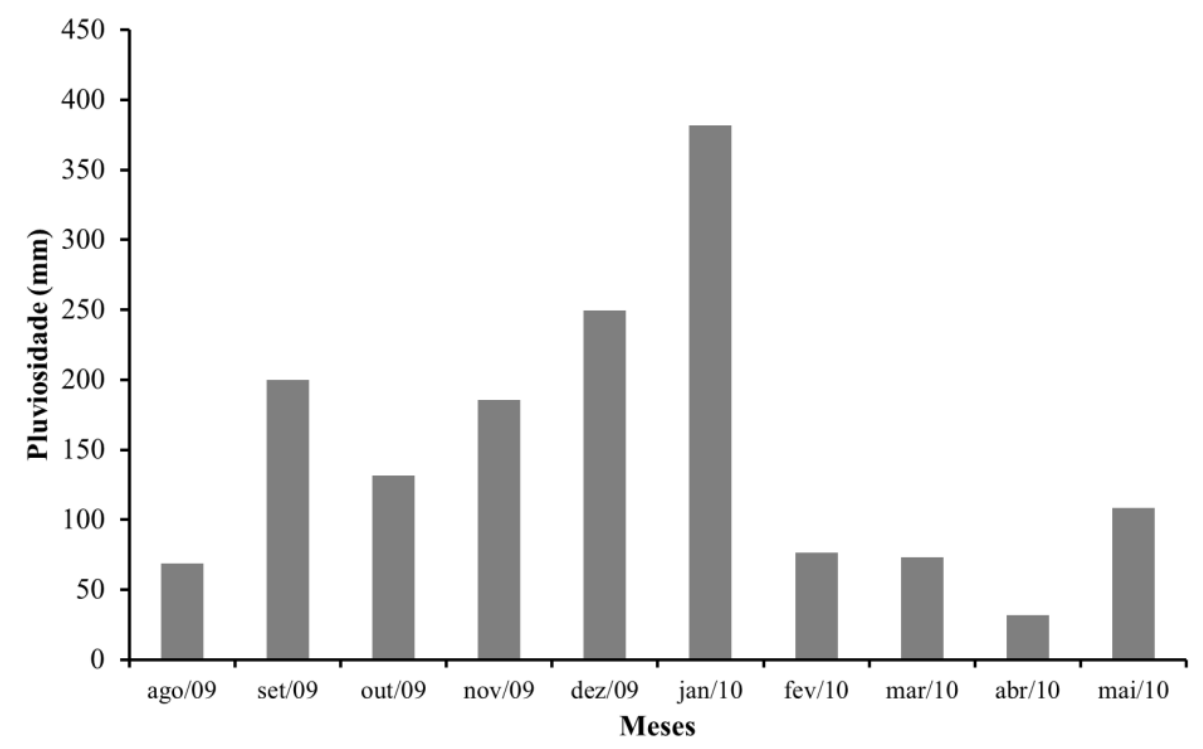

Fonte: Elaboração dos autores. 
O delineamento experimental utilizado foi em blocos ao acaso, com os tratamentos dispostos em esquema fatorial $3 \times 3 \times 5$, sendo os fatores: culturas de cobertura (milheto (Penisetum glaucum) e painço (Panicum miliaceum)) e um controle (pousio), doses de $\mathrm{K}_{2} \mathrm{O}\left(0 ; 50\right.$ e $100 \mathrm{~kg} \mathrm{ha}^{-1}$ de $\mathrm{K}_{2} \mathrm{O}$ ) e modos de aplicação do K (100\% nas plantas de cobertura; $100 \%$ na semeadura da soja; $100 \%$ em cobertura na soja; $50 \%$ antecipada nas culturas de cobertura $+50 \%$ na semeadura da soja; $50 \%$ na semeadura da soja $+50 \%$ em cobertura na soja) com quatro repetições. As parcelas continham 3,5m de largura e $6,0 \mathrm{~m}$ de comprimento $\left(21 \mathrm{~m}^{2}\right)$. No caso das culturas de cobertura, para análise, foi utilizado o fatorial de $2 \times 3 \times 3$, pelo fato de não considerar a área de pousio e as aplicações que não envolveram antecipação nas culturas de cobertura e somente terem efeito na soja em sucessão.

A semeadura das culturas de cobertura foi realizada em 29/10/2009, com semeadora apropriada, sem utilização de adubação na base, após o preparo do solo, com grade aradora e niveladora. Tanto o milheto como o painço, foram semeados em espaçamento de $0,34 \mathrm{~m}$ entre linhas. A aplicação de $\mathrm{K}_{2} \mathrm{O}$ antecipada nas culturas de cobertura ou área em pousio foi realizada a lanço em 10/12/09, em pleno período de desenvolvimento vegetativo das plantas. Em 18/12/2009 (50 dias após a semeadura - DAS) as culturas de cobertura e plantas daninhas que germinaram na área em pousio foram manejadas quimicamente, com herbicida a base de glifosate (960 g.i.a ha ${ }^{-1}$ ), para a implantação da cultura da soja na forma de semeadura direta. A área de pousio possuía poucas plantas daninhas, sendo que as que foram identificadas na área foram o Capim colchão (Digitaria sanguinales) e a Cordade-viola (Ipomea triloba L.).

A semeadura da soja foi realizada mecanicamente em 05/01/2010, utilizando-se a variedade MGBR 46 (Conquista), recomendada para solos de baixa e média fertilidade, de ciclo precoce, hábito de crescimento determinado, altura média de plantas de 0,80 m, com densidade populacional recomendada de 220 a $250 \mathrm{mil} \mathrm{ha}^{-1}$. O espaçamento foi de 0,45 $\mathrm{m}$ nas entrelinhas e densidade de 18 sementes por metro de sulco. Pelo fato da semeadura ter sido realizada após a época recomendada, houve a necessidade de aumento da população de plantas, devido a influência do fotoperíodo, pois as plantas florescem mais cedo, com menor desenvolvimento vegetativo nessa época. A adubação básica utilizada para a semeadura foi de $90 \mathrm{~kg} \mathrm{ha}^{-1} \mathrm{de}_{2} \mathrm{O}_{5}$ utilizando como fonte o superfosfato simples. $\mathrm{O} \mathrm{K}$ referente a semeadura da soja, nos respectivos tratamentos, foi aplicado dez dias após a semeadura, na superfície do solo e ao lado das plântulas recém emergidas, utilizando como fonte o $\mathrm{KCl}$. A aplicação do $\mathrm{K}$ em cobertura na soja foi realizada no estádio V6, a lanço.

O tratamento e inoculação das sementes, população de plantas, manejo de plantas daninhas e o manejo fitossanitário foram realizados de acordo com as recomendações da Embrapa (2008).

As avaliações realizadas nas culturas de cobertura foram: matéria seca (MS) e teor de K na parte aérea das plantas. Para a MS, logo após a dessecação, foi realizada uma amostragem da parte área das culturas de cobertura, coletando-se uma linha de 1,0 de comprimento na área central da parcela. $\mathrm{O}$ material vegetal obtido foi levado ao laboratório colocado em estufa de circulação forçada a $65{ }^{\circ} \mathrm{C}$ por 72 $\mathrm{h}$, sendo posteriormente pesado para o cálculo da quantidade de matéria seca produzida $\left(\mathrm{kg} \mathrm{ha}^{-1}\right)$. O material obtido, após secagem e pesagem, foi moído em moinho tipo Willey, para determinação do teor de K segundo metodologia de Malavolta, Vitti e Oliveira (1997). Pela pequena quantidade de plantas daninhas presentes na área de pousio não foi realizada amostragens nessas parcelas.

$\mathrm{Na}$ cultura da soja foi avaliado o teor de $\mathrm{K}$ nas folhas, sendo coletadas na área útil de cada parcela, em 30 plantas, a terceira folha totalmente desenvolvidas a partir do ápice na haste principal no florescimento pleno da soja (estádio R2), conforme metodologia de Raij et al. (1997). A determinação 
do teor de $\mathrm{K}$ foi realizada segundo metodologia de Malavolta, Vitti e Oliveira (1997). No estádio $\mathrm{R} 8$, foram coletadas 10 plantas aleatoriamente na área útil de cada parcela para determinação dos componentes de rendimento: número de vagens por planta e grãos por vagem. Para produtividade de grãos, colheu-se todas as plantas em duas linhas, com 3,0 m de comprimento, na área central da parcela. As plantas foram trilhadas e os grãos foram pesados com simultânea determinação da umidade para correção da pesagem para 13\% base úmida. Nos grãos obtidos de cada parcela foi realizada uma amostragem para determinação da massa de 100 grãos.

Os dados obtidos foram analisados estatisticamente pelo teste $\mathrm{F}$ e as médias comparadas pelo teste de Tukey ao nível de 5\% de probabilidade, para as culturas de cobertura, modos e doses de aplicação, utilizando-se programa estatístico Sisvar 5.0 (FERREIRA, 2003).

\section{Resultados e Discussão}

Em relação ao teor de $\mathrm{K}$ nas culturas de cobertura houve efeito isolado de todos os fatores estudados (Tabela 1). Para as culturas de cobertura a maior concentração foi observada no milheto, sendo uma característica da espécie apresentar elevada reciclagem desse nutriente. Salton e Hernani (1994) observaram que o milheto acumulou na parte aérea cerca de $377 \mathrm{~kg} \mathrm{ha}^{-1}$ de K. No painço, Lima et al. (2005) constataram acúmulo de $102 \mathrm{~kg}$ de $\mathrm{K} \mathrm{ha}^{-1}$ na matéria seca. Considerando que todo o $\mathrm{K}$ contido nos resíduos vegetais tenha sido liberado para soja em sucessão, a inclusão do milheto e do painço, em média, proporcionou um acumulo na parte aérea de 171 e $39 \mathrm{~kg} \mathrm{ha}^{-1}$ de $\mathrm{K}$, respectivamente.

Tabela 1. Valores de F, teores médios de K na parte aérea e médias de matéria seca (MS) das culturas de cobertura em função de doses e formas de aplicação de potássio. Selvíria-MS, 2009/2010.

\begin{tabular}{|c|c|c|}
\hline Tratamentos & $\mathbf{K}$ & MS \\
\hline Cobertura (C) & $\mathrm{g} \mathrm{kg}^{-1}$ & $\mathrm{~kg} \mathrm{ha}^{-1}$ \\
\hline Milheto & $45,01 \mathrm{a}$ & 3818 \\
\hline Painço & $33,05 \mathrm{~b}$ & 1192 \\
\hline \multicolumn{3}{|l|}{ Modos de Aplicação (M) } \\
\hline Antecipada & $40,73 \mathrm{a}$ & 2461 \\
\hline $1 / 2$ Antecipada $+1 / 2$ Semeadura & $37,73 \mathrm{~b}$ & 2549 \\
\hline \multicolumn{3}{|l|}{$\operatorname{Doses} K(K)\left(\mathrm{kg} \mathrm{ha}^{-1}\right)$} \\
\hline 0 & $41,91 \mathrm{a}$ & 1552 \\
\hline 50 & $36,77 \mathrm{~b}$ & 2519 \\
\hline 100 & $39,00 \mathrm{ab}$ & 3443 \\
\hline \multicolumn{3}{|l|}{ Valor de F } \\
\hline Cobertura (C) & $75,57 * *$ & $479,33 * *$ \\
\hline $\operatorname{Modos}(\mathrm{M})$ & $5,07^{*}$ & $0,53 \mathrm{~ns}$ \\
\hline Doses K (K) & $5,00^{*}$ & $82,84 * *$ \\
\hline $\mathrm{C} \times \mathrm{M}$ & $0,08 \mathrm{~ns}$ & $1,21 \mathrm{~ns}$ \\
\hline $\mathrm{C} \times \mathrm{K}$ & $2,21 \mathrm{~ns}$ & $77,50 * *$ \\
\hline $\mathrm{M} \times \mathrm{K}$ & $3,15 \mathrm{~ns}$ & $10,34 * *$ \\
\hline $\mathrm{C} \times \mathrm{M} \times \mathrm{K}$ & $0,26 \mathrm{~ns}$ & $52,69 * *$ \\
\hline CV (\%) & 11,74 & 16,59 \\
\hline Média Geral & 39,23 & 2505 \\
\hline
\end{tabular}

${ }^{\mathrm{ns}}$ não significativo; * Significativo a 5\% de probabilidade pelo Teste F; ** Significativo a 1\% de probabilidade pelo Teste F.

${ }^{1}$ Médias seguidas por mesma letra na coluna não diferem entre si pelo teste de Tukey, ao nível de 5\% de probabilidade

Fonte: Elaboração dos autores. 
Em relação às formas de aplicação, a aplicação do $\mathrm{K}_{2} \mathrm{O}$ totalmente antecipada nas culturas de cobertura proporcionou teor significativamente maior que a aplicação onde somente metade da adubação potássica foi antecipada, o que pode ser explicado pela maior quantidade utilizada, que resultou em maior disponibilidade de $\mathrm{K}$ no solo para as plantas. Para as doses de $\mathrm{K}_{2} \mathrm{O}$, verificou-se que houve valores semelhantes na concentração tanto na ausência de aplicação, como na maior dose, o que pode estar relacionado ao bom teor de K presente no solo e disponível para as plantas.

Em relação à matéria seca das culturas de cobertura (Tabela 1), verificou-se interação dessas com as doses e formas de aplicação de potássio. $\mathrm{Na}$ tabela 2, observa-se que independente da dose e forma de aplicação, o milheto produziu maior quantidade de matéria seca. Na comparação entre as duas formas de aplicação, na dose de $50 \mathrm{~kg}$ ha1, a antecipação total do $\mathrm{K}$ proporcionou menor conteúdo de matéria seca no milheto e maior no painço. No entanto, com $100 \mathrm{~kg} \mathrm{ha}^{-1}$ de $\mathrm{K}_{2} \mathrm{O}$, a aplicação totalmente antecipada no milheto foi a que proporcionou o maior acúmulo de matéria seca, em relação às demais. No painço com a maior dose a produção de matéria seca foi maior quando houve o parcelamento.

Tabela 2. Desdobramento da interação culturas de cobertura x modos de aplicação $\mathrm{x}$ doses de $\mathrm{K}_{2} \mathrm{O}$ significativa para matéria seca da parte aérea das culturas de cobertura. Selvíria - MS, 2009/2010¹.

\begin{tabular}{|c|c|c|c|c|c|c|}
\hline & \multicolumn{6}{|c|}{ Dose $\mathrm{K}_{2} \mathrm{O}\left(\mathrm{kg} \mathrm{ha}^{-1}\right)$} \\
\hline & \multicolumn{2}{|c|}{0} & \multicolumn{2}{|c|}{50} & \multicolumn{2}{|c|}{100} \\
\hline & Milheto & Painço & Milheto & Painço & Milheto & Painço \\
\hline Formas de apliçação & \multicolumn{6}{|c|}{ Matéria seca $\left(\mathrm{kg} \mathrm{ha}^{-1}\right)$} \\
\hline $\mathrm{AN}^{(2)}$ & $1957 \mathrm{aA}$ & $1047 \mathrm{aB}$ & $2488 \mathrm{bA}$ & $1800 \mathrm{aB}$ & $6677 \mathrm{aA}$ & $794 \mathrm{bB}$ \\
\hline \multirow[t]{4}{*}{$1 / 2 \mathrm{AN}+1 / 2 \mathrm{SE}^{(3)}$} & $2079 \mathrm{aA}$ & $1125 \mathrm{aB}$ & $4931 \mathrm{aA}$ & $858 \mathrm{bB}$ & $4774 \mathrm{bA}$ & $1526 \mathrm{aB}$ \\
\hline & \multicolumn{6}{|c|}{ Formas de aplicação } \\
\hline & $\mathrm{AN}^{(2)}$ & $1 / 2 \mathrm{AN}+$ & & $\mathrm{AN}^{(2)}$ & $1 / 2 \mathrm{~A}$ & $+1 / 2 \mathrm{SE}^{(3)}$ \\
\hline & \multicolumn{3}{|c|}{ Milheto } & \multicolumn{2}{|c|}{ Painço } & \\
\hline Doses & \multicolumn{6}{|c|}{ Matéria seca $\left(\mathrm{kg} \mathrm{ha}^{-1}\right)$} \\
\hline 0 & $1957 \mathrm{~b}$ & 207 & & $1047 \mathrm{~b}$ & & \\
\hline 50 & $2488 \mathrm{~b}$ & 493 & & $1800 \mathrm{a}$ & & \\
\hline 100 & $6677 \mathrm{a}$ & 477 & & $794 \mathrm{~b}$ & & \\
\hline
\end{tabular}

${ }^{1}$ Médias seguidas por mesma letra minúscula na coluna e maiúscula na linha (dentro da mesma dose) não diferem pelo teste de Tukey, ao nível de $5 \%$ de probabilidade. ${ }^{(2)}$ Antecipada; ${ }^{(3)} 1 / 2$ Antecipada $+1 / 2$ Semeadura.

Fonte: Elaboração dos autores.

Considerando as doses aplicadas (Tabela 2) verificou-se que nas duas formas de aplicação houve incremento de matéria seca quando se aplicou $\mathrm{K}$ no milheto, sendo que a dose maior (100 $\mathrm{kg} \mathrm{ha}{ }^{-1}$ ) proporcionou maior ganho significativo quando aplicada totalmente antecipada, no entanto, mesmo quando realizou-se parcelamento houve incremento significativo em relação a dose 0 . No painço, a aplicação de $50 \mathrm{~kg} \mathrm{ha}^{-1}$ totalmente antecipada aumentou significativamente a matéria seca, enquanto que o parcelamaneto não influenciou significativamente.
No geral, houve baixa produtividade de matéria seca das culturas de cobertura. Esse resultado difere dos encontrados por Lima et al. (2005) que, semeando as culturas em janeiro, sem aplicação de $\mathrm{K}$ e com período de manejo químico semelhante ao do presente trabalho, obtiveram produtividade de matéria seca de 10 e $5,6 \mathrm{t} \mathrm{ha}^{-1}$, de milheto e painço, respectivamente. Segundo esse mesmo autor, o milheto e em seguida, o painço, conduzidos no verão, em curto período de desenvolvimento (53 dias após a emergência), foram as coberturas 
vegetais que produziram as maiores quantidades de MS e, consequentemente, o maior acúmulo de macronutrientes na parte aérea. Os autores ressaltam ainda que, em um curto período de desenvolvimento, o milheto foi a cultura de cobertura que apresentou o maior potencial de produção de matéria seca, além da sua rusticidade, rapidez na formação da cobertura, ciclo adequado e características ecofisiológicas compatíveis com o local e a época de cultivo, o que está de acordo com os resultados do presente trabalho, no qual o milheto apresentou maior produtividade de matéria seca em período curto de tempo, em relação ao painço. A vantagem do painço seria a possiblidade de colheita dos grãos antes do manejo da fitomassa, com retorno financeiro em curto prazo.

$\mathrm{Na}$ Tabela 3, verifica-se os valores médios do teor de $\mathrm{K}$ nas folhas de soja, número de vagens planta $^{-1}$, número de grãos vagem ${ }^{-1}$, massa de 100 grãos e produtividade de grãos. Houve interação CxMxK para número de vagens planta $^{-1}$ e teor de $\mathrm{K}$ nas folhas, enquanto que para a massa de 100 grãos observou-se interação entre CxK. Para produtividade de grãos e grãos vagem ${ }^{-1}$ não houve significância para nenhum fator.

Tabela 3. Valores de F, médias de teor de $\mathrm{K}$ nas folhas de soja e características agronômicas: número de vagens planta $^{-1}$, número de grãos vagem ${ }^{-1}$, massa de 100 grãos e produtividade de grãos em função de culturas de cobertura, modos de aplicação e doses de $\mathrm{K}_{2} \mathrm{O}$. Selviria-MS, 2009/20101.

\begin{tabular}{|c|c|c|c|c|c|}
\hline Tratamentos & Teor de K & $\begin{array}{c}\text { Vagens } \\
\text { planta }^{-1} \\
\end{array}$ & $\begin{array}{c}\text { Grãos } \\
\text { vagem }^{-1}\end{array}$ & $\begin{array}{c}\text { Massa de } 100 \\
\text { grãos }\end{array}$ & $\begin{array}{c}\text { Produtividade de } \\
\text { grãos }\end{array}$ \\
\hline & $\mathrm{g} \mathrm{kg}^{-1}$ & --- & -- & g & $\mathrm{kg} \mathrm{ha}^{-1}$ \\
\hline \multicolumn{6}{|l|}{ Culturas de Cob. } \\
\hline Milheto & 27,0 & 44,5 & 1,6 & 18,8 & 2456 \\
\hline Painço & 27,2 & 45,7 & 1,7 & 18,4 & 2353 \\
\hline Pousio & 21,8 & 46,9 & 1,7 & 18,7 & 2376 \\
\hline \multicolumn{6}{|l|}{ Modos de Aplicação } \\
\hline Antecipada & 25,6 & 47,6 & 1,7 & 18,6 & 2440 \\
\hline Semeadura & 24,4 & 43,4 & 1,6 & 18,6 & 2403 \\
\hline Cobertura & 25,0 & 45,5 & 1,6 & 18,6 & 2355 \\
\hline $1 / 2 \mathrm{AN}+1 / 2 \mathrm{SE}^{(2)}$ & 25,4 & 47,6 & 1,7 & 18,6 & 2417 \\
\hline $1 / 2 \mathrm{SE}+1 / 2 \mathrm{CO}^{(3)}$ & 26,2 & 44,3 & 1,6 & 18,5 & 2361 \\
\hline \multicolumn{6}{|l|}{ Doses K $\left(\mathrm{Kg} \mathrm{ha}^{-1}\right)$} \\
\hline 0 & 24,0 & 45,3 & 1,7 & 18,7 & 2388 \\
\hline 50 & 27,4 & 45,9 & 1,6 & 18,5 & 2414 \\
\hline 100 & 24,6 & 45,9 & 1,7 & 18,6 & 2383 \\
\hline \multicolumn{6}{|l|}{ Valor de F } \\
\hline Cobertura $(\mathrm{C})$ & $40,70 * *$ & $1,37 \mathrm{~ns}$ & $0,29 \mathrm{~ns}$ & $4,85^{* *}$ & $1,53 \mathrm{~ns}$ \\
\hline $\operatorname{Modos}(\mathrm{M})$ & $1,21 \mathrm{~ns}$ & $2,00 \mathrm{~ns}$ & $0,53 \mathrm{~ns}$ & $1,11 \mathrm{~ns}$ & $0,42 \mathrm{~ns}$ \\
\hline Doses de $\mathrm{K}_{2} \mathrm{O}(\mathrm{K})$ & $14,34 * *$ & $0,11 \mathrm{~ns}$ & $1,75 \mathrm{~ns}$ & $1,32 \mathrm{~ns}$ & $0,14 \mathrm{~ns}$ \\
\hline $\mathrm{C} \times \mathrm{M}$ & $0,87 \mathrm{~ns}$ & $1,79 \mathrm{~ns}$ & $0,33 \mathrm{~ns}$ & $1,30 \mathrm{~ns}$ & $0,70 \mathrm{~ns}$ \\
\hline $\mathrm{C} \times \mathrm{K}$ & $4,62 * *$ & $1,92 \mathrm{~ns}$ & $0,03 \mathrm{~ns}$ & $3,29 *$ & $0,34 \mathrm{~ns}$ \\
\hline $\mathrm{MxK}$ & $7,09 * *$ & $1,83 \mathrm{~ns}$ & $1,07 \mathrm{~ns}$ & $1,48 \mathrm{~ns}$ & $1,25 \mathrm{~ns}$ \\
\hline $\mathrm{C} \times \mathrm{M} \times \mathrm{K}$ & $2,42 * *$ & $1,96^{*}$ & $0,62 \mathrm{~ns}$ & $0,76 \mathrm{~ns}$ & $1,47 \mathrm{~ns}$ \\
\hline CV $(\%)$ & 14,6 & 17,4 & 11,5 & 3,2 & 14,0 \\
\hline Média Geral & 25,3 & 45,7 & 1,6 & 18,6 & 2395,6 \\
\hline
\end{tabular}

(2) $1 / 2$ Antecipada $+1 / 2$ Semeadura ; (3) $1 / 2$ Semeadura $+1 / 2$ Cobertura.

ns: não significativo; *Significativo a 5\% de probabilidade pelo Teste F; ** Significativo a 1\% de probabilidade pelo Teste F.

Fonte: Elaboração dos autores. 
Verifica-se na Tabela 4, que a maioria dos teores de $\mathrm{K}$ nas folhas de soja estão próximos ou acima do limite superior da faixa considerada suficiente ou média (17,0 a 25,0 $\mathrm{g} \mathrm{kg}^{-1}$ ), segundo Embrapa (2010). De acordo com Meurer (2006) as plantas têm a capacidade de absorver quantidade de $\mathrm{K}$ superior à sua necessidade, o que comumente é denominado consumo de luxo de $\mathrm{K}$.

Para as formas de aplicação de potássio em função das doses e culturas de cobertura, na dose de $50 \mathrm{~kg} \mathrm{ha}^{-1}$ houve diferença significativa para os teores de $\mathrm{K}$ na soja cultivada em sucessão ao painço, com teor maior para aplicação $1 / 2$ antecipada $+1 / 2$ semeadura, no entanto, somente diferiu da aplicação na semeadura da soja. Na dose de 100 $\mathrm{kg}$ ha $^{-1}$ observou-se maior concentração com a aplicação 1/2 semeadura $+1 / 2$ cobertura no milheto.

Na comparação entre as culturas de cobertura, de modo geral, o milheto e o painço proporcionaram maior teor de $\mathrm{K}$ nas folhas de soja que a área de pousio, o que pode ser explicado pela absorção desse $\mathrm{K}$ aplicado por essas culturas de cobertura e liberação gradativa posteriormente, sendo que na área de pousio esse $\mathrm{K}$ pode ter sido perdido por escorrimento superficial, pois sem uma cobertura de solo e com o alto índice pluviométrico no mês em que foi semeada a soja esse K pode ter sido carreado com maior facilidade. No entanto, nas aplicações em cobertura não houve diferença entre as culturas e a área de pousio, principalmente pelo fato do $\mathrm{K}$ estar sendo aplicado mais tardiamente, momento em que a cultura da soja está com maior necessidade e capacidade de absorção mais rápida, com menor possibilidade de perdas do nutriente.

Em relação às doses aplicadas, verifica-se que na soja cultivada em sucessão ao milheto que não houve tendência a maior concentração com o aumento das doses aplicadas. Segundo Raij (1991) e Malavolta, Vitti e Oliveira (1997) com aumento na taxa de absorção, há um consequente incremento no seu teor na planta, até atingir o nível crítico, a partir do qual existe pequena probabilidade de resposta em produção. Continuando o suprimento do nutriente, o teor desse nos tecidos tende a aumentar, caracterizando consumo de luxo. Ultrapassado esse limite, o acúmulo torna-se excessivo, gerando consequências negativas, como queda no crescimento e desenvolvimento das plantas e potencialmente diminuição da absorção de outros nutrientes. Com isso, o alto teor de $\mathrm{K}$ do solo, juntamente com a maior dose aplicada pode ter ocasionado uma toxidez imperceptível nas plantas, fazendo com que a planta não absorvesse mais $\mathrm{K}$ após certo nível, e até diminuísse o teor nas folhas pelo desequilíbrio causado pelo teor excessivo.

Borkert et al. (2005b) afirmam que a faixa de suficiência no tecido vegetal estabelecida de 17,1 a $25,0 \mathrm{~g} \mathrm{~kg}^{-1}$ de $\mathrm{K}$, pode ser suprida por disponibilidade de K-trocável no solo, na faixa de $0,12 \mathrm{cmol}_{\mathrm{c}} \mathrm{dm}^{-3}$ a $0,50 \mathrm{cmol}_{\mathrm{c}} \mathrm{dm}^{-3}$ faixa em que se encontrava o teor no solo. Zancanaro, Tessaro e Hillesheim (2002), trabalhando com solos arenosos em Mato Grosso, relataram que em dois anos consecutivos, com teores de $\mathrm{K}$ de $16 \mathrm{~g} \mathrm{~kg}^{-1}$ e $17 \mathrm{~g} \mathrm{~kg}^{-1}$ nas folhas de soja, foram obtidos $90 \%$ da produtividade máxima, porém, as maiores produtividades foram obtidas na faixa de $20 \mathrm{~g} \mathrm{~kg}^{-1}$ a $24 \mathrm{~g} \mathrm{~kg}^{-1}$ de $\mathrm{K}$. Os teores de $\mathrm{K}$ verificados nesse trabalho foram superiores aos encontrados por Barbosa (2009) trabalhando com soja em sucessão ao milheto em solo semelhante, onde obteve-se média de 18,4 $\mathrm{g} \mathrm{kg}^{-1}$ da MS nas folhas de soja, sendo que no presente trabalho houve tratamentos que ultrapassaram $30 \mathrm{~g} \mathrm{~kg}^{-1} \mathrm{da}$ MS. Sabendo-se da necessidade de manutenção do bom teor de K no solo, jusifica-se a aplicação de $\mathrm{K}$ mesmo em solo com teor mais elevado e nesse caso, pode-se ter a possibilidade de aplicação de forma diferente da convencional, podendo ser mais eficiente sem comprometer o estado nutricional da planta. 


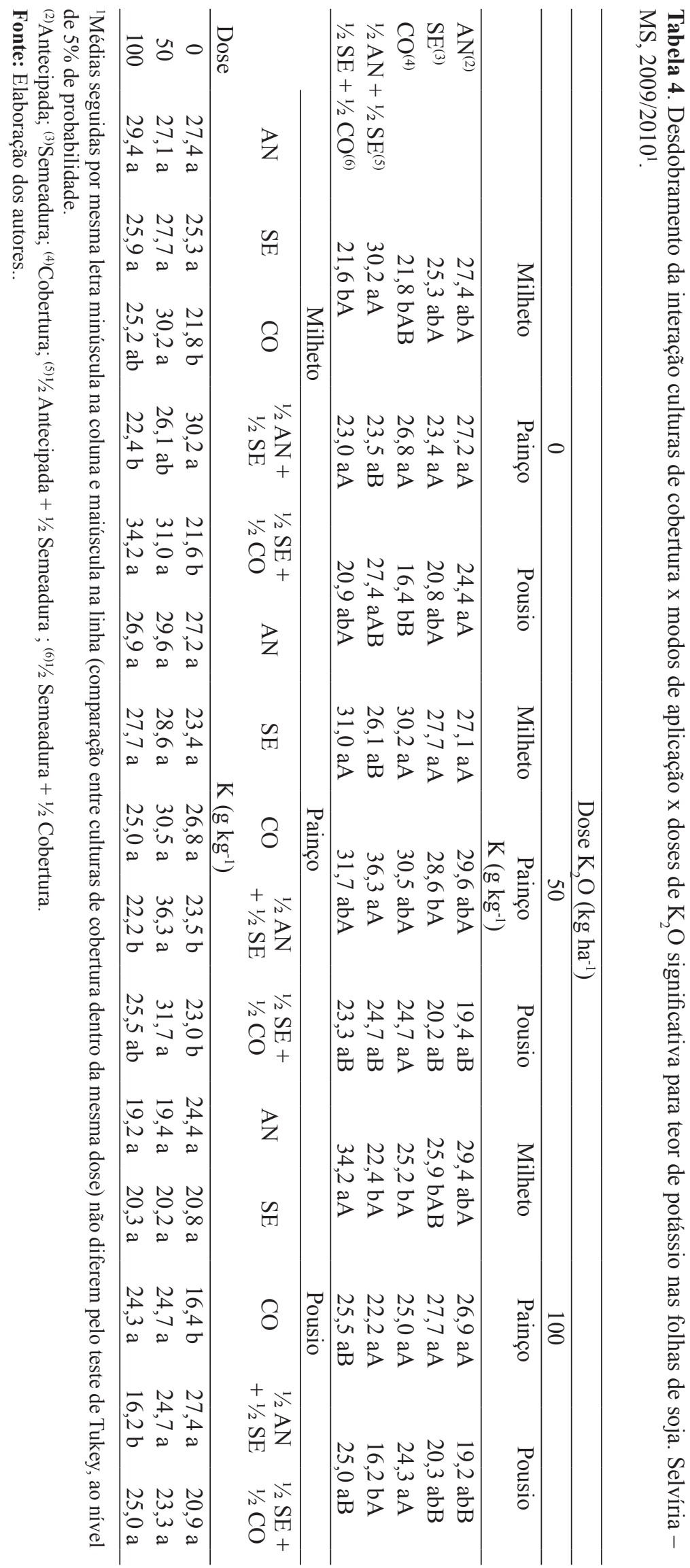




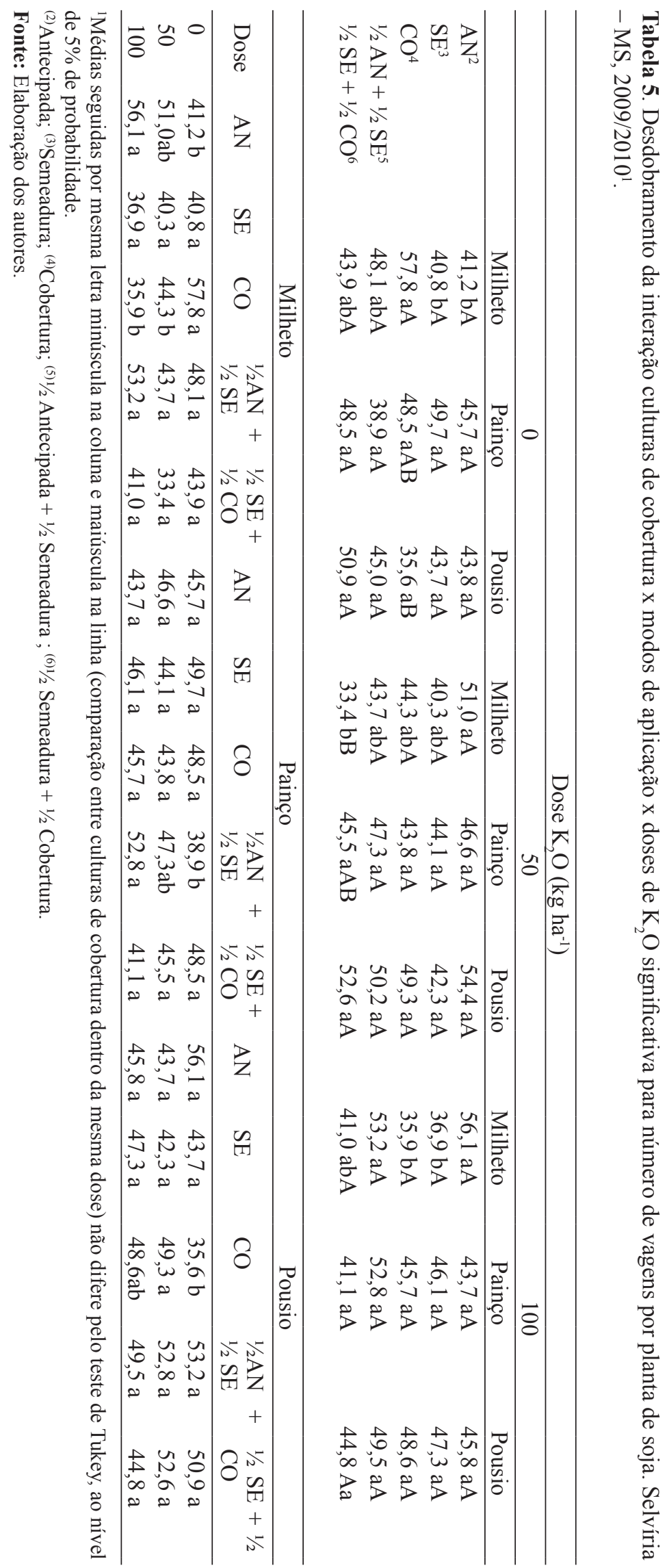


$\mathrm{Na}$ Tabela 5, verifica-se o desdobramento da interação tripla para o número de vagens planta $^{-1}$. Para os modos de aplicação de $\mathrm{K}$, nas doses aplicadas, só houve diferença significativa no milheto, em que a aplicação de $50 \mathrm{~kg}$ de $\mathrm{K}_{2} \mathrm{O}$ antecipada proporcionou maior número de vagens por planta, sendo superior somente a aplicação $1 / 2$ semeadura $+1 / 2$ cobertura. Com $100 \mathrm{~kg}$ de $\mathrm{K}_{2} \mathrm{O}$ ha $^{-1}$ obteve-se o maior número vagens planta $^{-1}$ nas aplicações antecipada e parceladas.

Analisando o número de vagens planta ${ }^{-1}$ de soja em relação a cada cultura de cobertura dentro de cada dose e forma de aplicação de $\mathrm{K}_{2} \mathrm{O}$, observase que na ausência de aplicação de $\mathrm{K}_{2} \mathrm{O}$, de forma geral, não foi observado aumento significativo no número de vagens planta $^{-1}$ para a soja em sucessão as culturas de cobertura em relação à área de pousio. Para a dose de $50 \mathrm{~kg}$ de $\mathrm{K}_{2} \mathrm{O}$ ha $^{-1}$ o número de vagens só foi influenciado com a aplicação em $1 / 2$ semeadura $+1 / 2$ cobertura, com quantidade de vagens significativamente superior na área de pousio em relação ao milheto. Na dose de $100 \mathrm{~kg}$ de $\mathrm{K}_{2} \mathrm{O}$ ha-1 não houve efeito significativo.

Em relação ao desdobramento do número de vagens planta $^{-1}$ conforme as doses aplicadas em diferentes formas de aplicação e culturas de cobertura pode-se observar pouca variação, sem aumento significativo para a maioria dos tratamentos. Rosolem, Bessa e Pereira (1993) também observaram ausência de resposta da adubação potássica na soja no número de vagens por planta. No entanto, Venturoso et al. (2009) constataram que a dose de $165 \mathrm{~kg} \mathrm{ha}^{-1}$ de $\mathrm{K}_{2} \mathrm{O}$ proporcionou aumento de $83 \%$ no número de vagens por planta, quando comparada ao tratamento testemunha, porém em solo com teor baixo de $\mathrm{K}$.

Na Tabela 6 tem-se o desdobramento da interação entre doses de $\mathrm{K}_{2} \mathrm{O}$ e as cultura de cobertura para a variável massa de 100 grãos. Verifica-se que para a dose 0 , o milheto promoveu a maior massa de 100 grãos, sendo estatisticamente superior a área com painço, o que pode ser explicado pela alta capacidade do milheto em extrair nutrientes do solo e disponibilizar para a cultura em sucessão (PEREIRA FILHO et al., 2005), no entanto esses valores ficaram muito próximos. Já na dose de $50 \mathrm{~kg} \mathrm{ha}^{-1} \mathrm{de}_{2} \mathrm{O}$, a área de pousio apresentou a maior média, enquanto que para a dose de $100 \mathrm{~kg} \mathrm{ha}^{-1}$ de $\mathrm{K}_{2} \mathrm{O}$ não houve diferença entre as médias obtidas. Na comparação das doses dentro de cada cultura, somente houve diferença para a soja em sucessão ao milheto, sendo que a ausência de aplicação proporcionou maior massa de 100 grãos, o que possivelmente se deve a quantidade suficiente de potássio disponível no solo. No entanto, em solos com baixo teor a massa de 100 grãos pode ter resposta positiva. Venturoso et al. (2009), observaram que o peso de 100 grãos apresentou resposta positiva com doses de potássio, sendo verificado acentuado incremento até a dose de $110 \mathrm{~kg} \mathrm{ha}^{-1}$ de $\mathrm{K}_{2} \mathrm{O}$ aplicado na semeadura da soja.

Tabela 6. Massa de 100 grãos de soja em função de culturas de cobertura e doses de potássio. Selvíria-MS, 2009/2010¹.

\begin{tabular}{lccc}
\hline \multirow{2}{*}{ Culturas de Cobertura } & \multicolumn{3}{c}{${\text { Dose } \mathrm{K}_{2} \mathrm{O}\left(\mathrm{kg} \mathrm{ha}^{-1}\right)}$} \\
\cline { 2 - 4 } & 0 & 50 & 100 \\
\cline { 2 - 4 } & & $---\mathrm{g}---$ & $18,89 \mathrm{aAB}$ \\
Milheto & $19,07 \mathrm{aA}$ & $18,47 \mathrm{abB}$ & $18,61 \mathrm{aA}$ \\
Painço & $18,48 \mathrm{bA}$ & $18,34 \mathrm{bA}$ & $18,56 \mathrm{aA}$ \\
\hline
\end{tabular}

${ }^{1}$ Médias seguidas por mesma letra minúscula na coluna e maiúscula na linha não diferem entre si pelo teste de Tukey, ao nível de $5 \%$ de probabilidade.

Fonte: Elaboração dos autores. 
Em relação à produtividade de grãos, não foi verificado efeito significativo dos tratamentos (Tabela 3). Provavelmente este resultado pode ser devido a área experimental utilizada apresentar valor alto de K no solo. Foloni e Rosolem (2008) também não observaram diferença para produtividade de grãos em três anos de cultivo, ressaltando ainda que a adubação potássica poderia ser antecipada totalmente na semeadura da cultura de cobertura. Os autores ainda constataram que independentemente das quantidades de $\mathrm{KCl}$ aplicadas na sucessão milheto-soja, a antecipação da adubação potássica da soja na semeadura do milheto minimizou a exportação de K via colheita de grãos de soja. Vale ressaltar que a produtividade média do presente estudo foi relativamente baixa, porém, está mais ligada a época de plantio realizada do que questões nutricionais.

Bernardi et al. (2009) também não encontraram resposta significativa para a produtividade da soja utilizando doses de 0,30, 60 e $180 \mathrm{~kg} \mathrm{ha}^{-1}$ aplicadas em pré-semeadura (a lanço) e na semeadura (no sulco), com e sem cobertura. Rosolem et al. (1984) e Vilela, Souza e Silva (2003) afirmaram que em solos com textura média a argilosa, com teor adequado de K trocável no solo, a adubação poderá ser a lanço, sem problema algum para a produtividade da soja, o que também foi confirmado por Guareschi et al. (2008). Em estudo de Pedroso Neto e Rezende (2005), a aplicação de K no plantio e parcelado proporcionou um aumento de 15,38\% (356 kg ha-1) e 13,26\% (307 $\left.\mathrm{kg} \mathrm{ha}^{-1}\right)$ em relação a aplicação em cobertura.

Em trabalho realizado por Borkert et al. (1997) em Latossolo Roxo eutrófico, que apresentava teor inicial de $\mathrm{K}$ trocável de $0,47 \mathrm{cmol}_{\mathrm{c}} \mathrm{dm}^{-3}$ (teor bem próximo ao do presente trabalho) com dez anos de duração, objetivando estudar a resposta da soja a adubação potássica e o efeito residual dessa adubação sobre o rendimento de grãos observaram que no tratamento controle (sem adubação), a produtividade decresceu somente a partir da oitava safra consecutiva sem adubação, período em que o teor do nutriente no solo chegou ao nível crítico. Em outro experimento realizado por Scherer (1998) somente houve redução da produtividade a partir da quinta safra consecutiva sem adubação potássica, atribuindo essa produtividade ao alto de teor de potássio disponível no solo $\left(3,2 \mathrm{mmol}_{\mathrm{c}} \mathrm{dm}^{3}\right)$ na instalação do experimento.

Por meio do presente trabalho e de trabalhos relatados pode-se constatar que nem sempre a aplicação de determinado nutriente no solo, resulta em retorno de produtividade, entretanto, é importante a realização da adubação de manutenção, pois ao longo dos anos sem a aplicação dessa adubação e com a exportação desse nutriente pela semente juntamente com as perdas por lixiviação há um decréscimo do mesmo no solo.

\section{Conclusões}

O milheto como planta de cobertura antecessora a cultura da soja produz maior conteúdo de matéria seca que o painço em curto período de tempo.

Em solo argiloso com alto teor de potássio não houve resposta a doses de potássio aplicadas, podendo a adubação potássica de manutenção ser aplicada totalmente antecipada na cultura de cobertura, na semeadura ou em cobertura na cultura de soja.

\section{Referências}

BARBOSA, C. E. M. Culturas de cobertura em região de inverno seco para semeadura direta da soja. 2009. Dissertação (Mestrado em Agronomia) - Faculdade de Engenharia de Ilha Solteira. Universidade Estadual Paulista, Ilha Solteira.

BERNARDI, A. C. C.; OLIVEIRA JÚNIOR, J. P.; LEANDRO, W. M.; MESQUITA, T. G. S.; FREITAS, P. L.; CARVALHO, M. C. S. Doses e formas de aplicação da adubação potássica na rotação soja, milheto e algodão em sistema de plantio direto. Pesquisa Agropecuária Tropical, Goiânia, v. 39, n. 2, p. 158-167, 2009. 
BONAMIGO, L. A. Milheto como cobertura no sistema de plantio direto, benefícios do melhoramento da cultura. In: ENCONTRO DE PLANTIO DIRETO NO CERRADO, 7., 2003, Sorriso. Anais... Cuiabá: UFMT, 2003. p. 37-48.

BORKERT, C. M.; CASTRO, C.; OLIVEIRA, F. A.; KLEPKER, D.; OLIVEIRA-JUNIOR, A. O potássio na cultura da soja. In: YAMADA, T.; ROBERTS, T. L. Potássio na agricultura brasileira. Piracicaba, POTAFÓS, 2005a. p. 671-713.

O potássio na cultura da soja. In: SIMPÓSIO SOBRE POTÁSSIO NA AGRICULTURA BRASILEIRA, 2., 2004, Piracicaba. Anais... Piracicaba: POTAFÓS, 2005b. v. 841, p. 671-722.

BORKERT, C. M.; SFREDO, G. J.; FARIAS, J. R. B.; TUTIDA, F.; SPOLADORI, C. L. Resposta da soja a adubação e disponibilidade de potássio em Latossolo Roxo eutrófico. Pesquisa Agropecuária Brasileira, Brasília, v. 32, n. 12, p. 1235-1249, 1997.

DEMATTÊ, J. L. I. Levantamento detalhado dos solos do Campus experimental de Ilha Solteira Piracicaba: ESALQ, 1980. 131 p.

EMPRESA BRASILEIRA DE PESQUISA AGROPECUÁRIA - EMBRAPA. Tecnologia de produção de soja - Região Central do Brasil - 2008. Londrina: Embrapa Soja: Embrapa Cerrados: Embrapa Agropecuária Oeste, 2008. 280 p.

- Tecnologias de produção de soja - região central do Brasil 2011. Londrina: Embrapa Soja: Embrapa Cerrados: Embrapa Agropecuária Oeste, 2010. 255 p.

FERREIRA, D. F. SISVAR sistema para análise de variância. Lavras: UFLA, 2003. (Software estatístico).

FOLONI, J. S. S.; ROSOLEM, C. A. Produtividade e acúmulo de potássio na soja em função da antecipação da adubação potássica no sistema plantio direto. Revista Brasileira de Ciência do Solo, Viçosa, v. 32, n. 4, p. 1549- 561, 2008.

FRANCISCO, E. A. B. Antecipação da adubação da soja na cultura de Eleusine coracana (L.) Gaertn., em sistema de plantio direto. 2002. Dissertação (Mestrado em Agronomia) - Escola Superior de Agricultura Luiz de Queiroz. Universidade de São Paulo, Piracicaba.

GUARESCHI, R. F.; GAZOLLA, P. R.; SOUCHIE, E. L.; ROCHA, A. C. Adubação fosfatada e potássica na semeadura e a lanço antecipada na cultura da soja cultivada em solo de Cerrado. Semina: Ciências Agrárias, Londrina, v. 29, n. 4, p. 769-774, 2008.
LIMA, E. V.; CRUSCIOL, C. A. C.; LEITÃO-LIMA, P. S.; CORRÊA, J. C. Espécies para cobertura e qualidade dos resíduos vegetais na implantação do sistema de plantio direto em região de inverno seco. Revista Brasileira de Milho e Sorgo, Sete Lagoas, v. 4, n. 2, p. 180-194, 2005.

MAlaVOlTA, E.; VITTI, G. C.; OLIVEIRA, S. A. Avaliação do estado nutricional das plantas: princípios e aplicações. 2. ed. Piracicaba: POTAFÓS, 1997. 319 p.

MATOS, M. A.; SALVI, J. V.; MILAN, M. Pontualidade na operação de semeadura e a antecipação da adubação e suas influências na receita liquida da cultura da soja. Engenharia Agrícola, Jaboticabal, v. 26, n. 2, p. 493-501, 2006.

MEURER, E. J. Potássio. In: FERNANDES, M. S. Nutrição mineral de plantas. Viçosa, MG: Universidade Federal de Viçosa, 2006. p. 281-298.

OLIVEIRA, F. A.; CASTRO, C.; SFREDO, G. J.; KLEPKER, D.; OLIVEIRA JUNIOR, A. Fertilidade do solo e nutrição mineral da soja. Londrina: Embrapa Soja, 2008. (Embrapa Soja. Circular técnica, 62).

PEDROSO NETO, J. C.; REZENDE, P. M. Doses de modos de aplicação de potássio na produtividade de grãos e qualidade de sementes de soja (Glycine max (L), MERRILL). FAZU em Revista, Uberaba, v. 1, n. 2, p. $27-$ 36, 2005.

PEREIRA FILHO, I. A.; RODRIGUES, J. A. S.; KARAM, D.; COELHO, A. M.; ALVARENGA, R. C.; CRUZ, J. C.; LARA CABEZAS, W. Manejo da cultura do milheto. In: MARTINS NETTO, D. A.; DURÃES, F. O. M. (Ed.). Milheto- tecnologias de produção $e$ agronegócio. Brasília: Embrapa Informação Técnológica, 2005. p. 60-92.

RAIJ, B. Van. Fertilidade do solo e adubação. Piracicaba: Ceres, 1991. 343 p.

RAIJ, B. V.; CANTARELLA, H.; QUAGGIO, J. A.; FURLANI, A. M. C. (Ed.). Recomendações de adubação e calagem para o Estado de São Paulo. 2. ed. Campinas: Instituto Agronômico de Campinas, Fundação IAC, 1997. $285 \mathrm{p}$.

ROSOlEM, C. A.; BESSA. A. M.; PEREIRA, H. F. M. Dinâmica do potássio no solo e nutrição potássica da soja. Pesquisa Agropecuária Brasileira, Brasília, v. 28, n. 9, p. 1045-1054, 1993.

Rosolem, C. A.; CAlOnEGO, J. C.; FOLONI, J. S. S. Lixiviação de potássio da palhada de espécies de cobertura de solo de acordo com a quantidade de chuva aplicada. Revista Brasileira de Ciência do Solo, Viçosa, v. 27, n. 2, p. 355-362, 2003. 
ROSOLEM, C. A.; NAKAGAWA, J.; MACHADO, J. R.; YAMADA, T. Adubação potássica da soja em Latossolo Vermelho-Escuro fase arenosa. Pesquisa Agropecuária Brasileira, Brasília, v. 19, n. 11, p. 1319-1326, 1984.

SALTON, J. C.; HERNANI, L. C. Cultivos de primavera: alternativa para produção de palha no Mato Grosso do Sul. In: REUNIÃO BRASILEIRA DE MANEJO E CONSERVAÇÃO DO SOLO E DA ÁGUA, 10., 1994, Florianópolis. Resumos... Florianópolis: Sociedade Brasileira de Ciência do Solo, 1994. p. 248-249.

SCHERER, E. E. Resposta da soja à adubação potássica em Latossolo Húmico distrófico num período de doze anos. Revista Brasileira de Ciência do Solo, Campinas, v. 22, n. 1, p. 49-55, 1998.

VENTUROSO, L. R.; BERGAMIM, A. C.; VALADÃO JÚNIOR, D. D.; LIMA, W. A.; OLIVEIRA, W. B.; SCHLINDWEIN, J. A.; CARON, B. O.; SCHIMIDT, D. Avaliação de duas cultivares de soja sob diferentes doses de potássio, no município de Rolim de Moura, RO. Agrarian, Dourados, v. 2, n. 4, p. 17-29, 2009.
VILELA, L.; SOUZA, D. M. G.; SILVA, J. E. Adubação potássica. In: SOUZA, D. M. G.; LOBATO, E. Cerrado: correção do solo e adubação. Planaltina: Embrapa Cerrados, 2003. p. 169-163.

ZANCANARO, L.; HILLESHEIM, J.; HOOGERHIDE, H.; VERONESE, M.; VILELA, L.; FRANCISCO, E. A. B. Manejo do solo, adubação e nutrição da cultura da soja. In: HIROMOTO, D. M.; CAJU, J.; CAMACHO, S. A. (Ed.). Boletim de pesquisa de soja 2009. Rondonópolis: Fundação MT, 2009. n. 13. p. 270-285.

ZANCANARO, L.; TESSARO, L. C.; HILLESHEIM, J. Adubação fosfatada e potássica da soja no cerrado. Informações Agronômicas, Piracicaba, n. 98, p. 1-5, 2002. 